\title{
REKAYASA SISTEM DRAINASE BERWAWASAN LINGKUNGAN PADA KAWASAN INDUSTRI PIYUNGAN KABUPATEN BANTUL, DAERAH ISTIMEWA YOGYAKARTA
}

\section{Triyono $^{1}$, Djoko Marsono ${ }^{2}$, dan Tukidal Yunianto ${ }^{3}$}

ITY “STTL YLH”, Yogyakarta", Fakultas Kehutanan", Fakultas Geografi, Universitas Gadjah Mada, Yogyakarta, Indonesia

trimitra.triyono@yahoo.com

Diterima : Maret 2014; Direvisi: Juni 2014; Dipubikasikan: 31 Maret 2015

\begin{abstract}
ABSTRAK Penelitian ini adalah rekayasa sistem drainase berwawasan lingkungan pada Kawasan Industri Piyungan Kabupaten Bantul Daerah Istimewa Yogyakarta. Obyek penelitian adalah rekayasa sistem drainase, dan tujuan penelitian yaitu melakukan kajian terhadap efektifitas penggunaan sistem drainase berwawasan lingkungan berupa sumur resapan, saluran resapan dan kolam resapan untuk meresapkan air hujan kedalam tanah sebagai fungsi konservasi air tanah. Penelitian ini menggunakan metode analisis deskriptif kualitatif dengan teknik pengumpulan adalah pengambilan sampel secara proporsional yang telah ditentukan dan mewakili keadaan obyek yang diteliti (purposive sampling). Analisis data dengan pendekatan empiris terhadap perencanaan sumur resapan, saluran resapan dan kolam resapan. Hasil rekayasa sistem drainase berwawasan lingkungan diperoleh nilai efektifitas penggunaan sumur resapan diameter $80 \mathrm{~cm}$ dan kedalaman 4 meter pada kawasan terbangun (C: 0,90) sebesar 29,96 \%, lahan campuran (C: 0,50) sebesar 26,97 \%, ruas jalan (C:0,80) sebesar $0 \%$ dan lahan terbuka (C: 0,30) sebesar 17,98 \%. Penggunaan saluran resapan berdasarkan ketentuan tipe jalan, diameter sumur resapan $40 \mathrm{~cm}$, kedalaman sumur 2 meter dan jarak antar sumur 10 meter, diperoleh efektifitas saluran resapan sebesar 2,54\%. Kolam resapan mempunyai kontribusi peresapan sebesar $25 \%\left(38.429,77 \mathrm{~m}^{3} /\right.$ tahun $)$ dari kapasitas total debit penampungan $152.719,07 \mathrm{~m}^{3} / \mathrm{tahun}$. Sistem drainase berwawasan lingkungan dengan koefisien permeabilitas tanah 4,66 cm/jam $\left(1,3 \mathrm{x} 10^{-3} \mathrm{~cm} / \mathrm{detik}\right)$ diperoleh nilai peresapan untuk sumur resapan: 18,73 \%, saluran resapan: 2,54 \% dan kolam resapan sebesar $25 \%$, sehingga dapat disimpulkan bahwa penggunaan sumur resapan dipadukan dengan kolam resapan lebih efektif dari saluran resapan.
\end{abstract}

Kata kunci: drainase; eko-drainase; kolam resapan; saluran resapan; sumur resapan.

\begin{abstract}
This study is ecodrainage system engineering in Piyungan Industrial Estate Bantul District of Yogyakarta Special Region. Object of research is engineered drainage systems, and research aims is a review of the effectiveness of the use of ecodrainage system in the form of infiltration wells, channel infiltration and infiltration ponds to absorb rain water infiltration into the soil as a function of soil water conservation. This study used a qualitative descriptive analysis method with collecting technique is proportional sampling predetermined and represent the state of the object under study. Data analysis with empirical approach to planning infiltration wells, infiltration channels and infiltration ponds. Engineered drainage system environmental values obtained effective use absorption wells diameter of $80 \mathrm{~cm}$ and a depth of 4 meters on the area awakened (C: 0.90) of 29.96\%, mixed land (C: 0.50) by 26.97\%, roads (C: 0.80) at 0\% and the open land (C: 0.30) of 17.98\%. The use of infiltration channels under the terms of the type of road, diameter $40 \mathrm{~cm}$ absorption wells, well depth of 2 meters and the distance between wells 10 meters, obtained effectiveness of absorption line at 2.54\%. Swimming infiltration infiltration contributes $25 \%\left(38429.77 \mathrm{~m}^{3} /\right.$ year) of the total discharge capacity of reservoirs $152,719.07 \mathrm{~m}^{3} /$ year. Ecodrainage system with soil permeability coefficient of $4.66 \mathrm{~cm} / \mathrm{h}\left(1.3 \times 10^{-3} \mathrm{~cm} / \mathrm{sec}\right)$ absorption values obtained for infiltration wells: $18.73 \%$, channel infiltration: $2.54 \%$ and infiltration ponds of $25 \%$, so it can be concluded that the use of infiltration wells combined with infiltration ponds more effective infiltration of the channel infiltration.
\end{abstract}

Key words: drainage; ecodrainage; infiltration ponds; channel in filtration; infiltration wells.

\section{PENDAHULUAN}

Kawasan Industri Piyungan (KIP) merupakan kawasan industri terpadu terdiri dari 5 sub kawasan berada di Desa Sitimulyo dan Desa Srimulyo Kecamatan Piyungan Kabupaten Bantul dengan luas total 123,55 Ha. KIP membutuhkan infrastruktur 
kawasan yang memadai guna mendukung kegiatan operasional kawasan, terutama infrastruktur jalan dan sistem drainase. Permasalahan terkait dengan sistem drainase KIP adalah belum tersedia prasarana sistem drainase yang memadai, hal ini akan mempengaruhi kegiatan operasional kawasan. Kondisi demikian akan mengakibatkan terjadinya permasalahan lingkungan, baik lingkungan dalam kawasan industri maupun sekitar kawasan. Sehingga daya dukung lingkungan akan semakin menurun seiring dengan kegiatan operasional KIP.

Permasalahan mendasar sistem drainase KIP adalah tercampurnya saluran drainase dan irigasi serta masuknya air buangan domestik ke dalam sistem drainase. Saluran drainase menggunakan drainase konvensional dimana limpasan air hujan langsung dialirkan menuju badan air terdekat. Lemahnya kesadaran masyarakat dalam pemeliharaan saluran sehingga terdapat endapan dan sampah yang mengganggu kinerja saluran drainase. Serta belum optimalnya jalur dan lahan hijau. Perlunya rekayasa sistem drainase berwawasan lingkungan melalui rekayasa fisik/teknis, biologi dan sosial, sehingga tercipta keseimbangan dan kelestarian fungsi lingkungan.

Tujuan penelitian ini adalah sebagai berikut: (a) melakukan kajian kondisi lingkungan dan rencana pengembangan Kawasan Industri Piyungan; dan (b) membuat rekayasa sistem drainase berwawasan lingkungan pada Kawasan Industri Piyungan.

Konsep drainase menurut ilmu teknik sipil adalah menarik air dari daerah genangan dengan sistem jaringan drainasenya kemudian mendorong air tersebut ke sungai terdekat yang akhirnya mengalir ke laut dengan istilah pull and push. Perpaduan konsep drainase berwawasan lingkungan selain mengalirkan air juga menyimpan dan menyembunyikan air sebagai fungsi konservasi dan kesehatan lingkungan. Tinjauan terhadap konservasi lingkungan adalah menyimpan air kembali dengan meresapkan air kedalam tanah sebagai tabungan air pada musim kemarau, dan tinjauan terhadap kesehatan lingkungan bahwa menyalurkan air dengan cara meresapkan kedalam tanah dapat mengurangi pencemaran lingkungan juga memutus rantai kehidupan nyamuk serta penataan ruangan lebih leluasa dan estetis. Pemanfaatan cekungan seperti taman kota dapat dipakai sebagai resapan dengan syarat elevasinya dibuat lebih rendah daripada jalan di sekitarnya (Hindarko, 2002).

Sumur resapan merupakan sumur atau lubang pada permukaan tanah yang dibuat untuk menampung air hujan agar dapat meresap ke dalam tanah. Beberapa fungsi sumur resapan bagi kehidupan manusia adalah sebagai pengendali banjir, melindungi dan menjaga konservasi air tanah, serta menekan laju erosi, (Kusnaedi, 2002). Sebagai pengendali banjir, sumur resapan mampu memperkecil aliran permukaan sehingga terhindar dari penggenangan aliran permukaan secara berlebihan yang menyebabkan banjir. Banyaknya aliran permukaan dapat dikurangi dengan pembuatan sumur resapan, yang tergantung pada volume dan jumlah sumur resapan yang terdapat pada suatu kawasan.

Lebih lanjut Suripin (2004) menambahkan konsep dasar pengembangan sistem drainase yang berkelanjutan adalah meningkatkan daya guna air, meminimalkan kerugian, serta memperbaiki dan konservasi lingkungan. Untuk itu diperlukan usahausaha yangkomprehensif dan integratif yang meliputi seluruh proses, baik yang bersifat structural maupun non struktural, untuk mencapai tujuan tersebut. Sampai saat ini perancangan drainase didasarkan pada filosofi bahwa air secepatnya mengalir dan seminimal mungkin menggenangi daerah layanan. Tapi dengan semakin timpangnya perimbangan air(kebutuhan dan ketersedian) maka diperlukan suatu perancangan drainase yang berfilosofi bukan saja aman terhadap genangan tapi juga sekaligus berasas pada konservasi air (Sunjoto, 1987).

Landasan teori ini mencakup pendekatan permasalahan sistem drainase lingkungan dan kerangka teori yang dibangun untuk mencari alternatif pemecahan masalah drainase. Pendekatan permasalahan sistem drainase berdasarkan kondisi nyata di lapangan dan hasil kajian literatur, antara lain diuraikan sebagai berikut:

(1) Komponen penting dalam rekayasa sistem drainase yaitu kondisi topografi, iklim, penggunaan lahan dan kependudukan;

(2) Pertumbuhan penduduk semakin meningkat membutuhkan sarana dan prasarana hidup yang berpengaruh pada perubahan penggunaan lahan dan perubahan perilaku yang cenderung menurun kualitasnya. Dampak yang muncul adalah saluran drainase tidak terpelihara, timbul endapan, sampah dan berkurangnya kapasitas saluran drainase serta menurunnya kualitas air.

(3) Kondisi topografi dalam kaitanya dengan batas DAS dan intensitas hujan berpengaruh pada timbulnya genangan dan sedimen akibat aliran permukaan (run off), dipicu dengan pertumbuhan penduduk meningkat dan kurang sadarnya penduduk terhadap pemeliharaan drainase.

(4) Permasalahan terakhir adalah infrastruktur drainase rusak dan kualitas lingkungan permukiman menurun. 
Keberadaan infrastruktur drainase di kawasan industri merupakan hal penting untuk mendukung keberadaan kawasan tersebut, karena kebutuhan prasarana drainase merupakan sebagian kebutuhan awal bagi sebuah kegiatan. Penelitian ini difokuskan pada bagaimana rekayasa sistem drainase berwawasan lingkungan ditinjau dari aspek fisik, biologi dan sosial sehingga dapat meningkatkan daya dukung lingkungan KIP. Rekayasa sistem drainase berwawasan lingkungan mengadopsi prinsip TRAP yaitu Tampung, Resapkan, Alirkan dan Pelihara. Lebih lanjut berikut ini diuraikan penjelasan kerangka teori yang dibangun untuk penyelesaian masalah, antara lain:

(1) Air hujan pada hakekatnya adalah air bersih yang dapat dipergunakan untuk pemenuhan kebutuhan air domestik sehari-hari, sehingga air hujan perlu dipanen dengan ditampung dan atau diresapkan. Air hujan dapat ditampung secara individual, komunal atau terpusat, baik melalui penampungan air hujan (PAH) di atas tanah maupun tangki bawah tanah (ground tank);

(2) Pemanenan air hujan dibagi menjadi 2 (dua) sistem berdasarkan penggunaan lahan, yaitu sistem internal dan sistem eksternal. Sistem internal meliputi kawasan permukiman dimana berdiri bangunan untuk rumah tangga, kantor dan industri. Pemanenan hujan dengan cara menampung air hujan yang jatuh di atas atap bangunan kemudian melalui talang dialirkan menuju PAH. Air hujan ditampung dan diolah melalui proses pengolahan sederhana dan bisa dipergunakan untuk kebutuhan air sehari-hari, sedangkan sisanya diresapkan ke dalam sumur resapan.

(3) Air hujan yang meluap dari sumur resapan dialirkan melalui saluran resapan menuju sistem eksternal (kolam resapan) dan atau menuju badan air penerima.

(4) Sistem eksternal mencakup penggunaan lahan lolos air (irigasi, ruang terbuka dan kolam resapan) dan kedap air (ruas jalan). Air hujan yang jatuh di atas lahan lolos air ditampung, diresapkan dan sisanya dialirkan menuju badan air penerima. Air hujan yang jatuh di atas lahan kedap air langsung dialirkan melalui saluran resapan menuju badan air penerima.

(5) Badan air penerima bisa berupa saluran primer, banjir kanal (long storage) dan sungai. Sungai merupakan media air terakhir sebelum mengalir ke laut dan air sungai dapat diolah dan dimanfaatkan kembali untuk berbagai kepentingan, yaitu air baku untuk air bersih domestik, industri, perikanan, pertanian, sarana olah raga dan rekreasi.
(6) Sistem drainase berwawasan lingkungan akan terwujud, berkelanjutan dan lestari kuncinya terletak di dalam pengelolaan drainase. Lembaga pengelolaan drainase adalah pemerintah, masyarakat dan swasta. Lembaga ini akan saling bekerja sama dan memperkuat dalam tahapan perencanaan, pelaksanaan, pengawasan, operasi dan pemeliharaan.

(7) Pemeliharaan prasarana drainase merupakan kunci terakhir yang sangat menentukan keberhasilan sistem drainase berwawasan lingkungan.

\section{METODE PENELITIAN}

Pendekatan penelitian sangat berperan penting dalam sebuah penelitian karena tercapai tidaknya suatu penelitian tergantung dari ketepatan dalam memilih metode penelitian. Metode yang digunakan dalam pemilihan titik sampling yaitu metode purposive sampling. Purposive sampling adalah sampel yang dipilih dengan cermat hingga relevan dengan desain penelitian (Mantra, 2004). Metode ini dipilih karena mempertimbangkan sistem drainase KIP yang sudah terbangun merupakan salah satu ciri penting dalam pengambilan sampel.

Teknis analisis data dengan analisis deskriptif kualitatif melalui pendekatan empiris terhadap kondisi prasarana drainase lingkungan di Kawasan Industri Piyungan. Analisis data mencakup analisis hidrologi, permeabilitas tanah, dan hidraulika drainase berwawasan lingkungan. Data hujan menggunakan pencatatan hujan di Stasiun Karangploso Piyungan, berdasarkan analisis hidrologi hasil uji distribusi hujan yang lebih cocok adalah Log-normal dengan data hujan 5 tahunan $\left(\mathrm{R}_{5}\right)$ sebesar $118,50 \mathrm{~mm}$ dan debit banjir $\left(\mathrm{Q}_{\mathrm{m}}=\right)$ 8,06 $\mathrm{m} 3 /$ detik, data koefisien permeabilitas tanah sebesar $4,66 \mathrm{~cm} /$ jam $\left(1,3 \times 10^{-3} \mathrm{~cm} /\right.$ detik $)$. Analisis hidraulika sistem drainase terbatas pada obyek kajian sumur resapan, saluran resapan dan kolam resapan.

Rekayasa sumur resapan meliputi kajian terhadap tinggimuka airtanah, luas atap bangunan, sebaran dan dimensi sumur resapan. Tinggi muka airtanah digunakan sebagai pertimbangan dalam penentuan lokasi pembuatan sumur resapan, data primer kedalaman air tanah tercatat rata-rata 9 meter dan arah aliran air tanah cenderung mengikuti arah kontur topografinya. Kedalaman muka airtanah diklasifikasikan dan dipetakan, kemudian digunakan untuk menguji efektifitas dimensi sumur resapan rencana. Luas atapdigunakan untuk menentukan besarnya air hujan yang kemungkinan dapat ditangkap oleh atap, yang selanjutnya akan mengalir dan ditampung dalam sumur resapan. Untuk menghitung 
besarnya debit air yang terjadi, maka perlu diketahui besarnya koefisien limpasan atap bangunan.Menurut Sunjoto (1992) besarnya koefisien limpasan untuk atap yang tidak rembes (tidak tembus air) adalah 0,9.Berdasarkan data luas atap, koefisien limpasan atap, dan intensitas hujan rancangan, maka dapat ditentukan besarnya debit air rancangan yang akan dimasukkan ke dalam sumur resapan. Untuk menentukan debit air rancangan digunakan rumus rasional dan dengan data luas atap bangunan KIP adalah sebesar $247.378 \mathrm{~m}^{2}$.

Sebaran sumur resapan dalam penelitian ini adalah wilayah dimana terdapat lahan peruntukan bangunan dan sumur resapan dipasang pada sekitar bangunan tersebut denga asumsi sebagai pengganti luas bidang kedap air. Sebaran sumur resapan ditentukan berdasarkan koefisien permeabilitas tanah dan keberadaan bangunan, serta pertimbangan kemudahan konstruksi. Dimensi sumur resapan adalah ukuranukuran meliputi jari-jari (R), tinggi dinding sumur kedap air yang direncanakan $(\mathrm{H})$. Penentuan dimensi sumur resapandigunakan data debit air rancangan yang masuk ke dalam sumur resapan, koefisien permeabilitas batuan, waktu pengaliran, dan faktor geometrik sumur resapan.Jenis sumur resapan rencana dalam penelitian ini merupakan sumur dengan seluruh dinding kedap air dengan faktor geometrik (F) dihitung dengan rumus (Sunjoto, 1990).

$$
F=2 . \pi . R \text {. }
$$

Pengujian koefisien permeabilitas tanah untuk mengetahui harga atau nilai permeabilitas tanah (k) dilakukan penelitian di lapangan dengan prinsip metode tabung (The pipe-Cavity Method) hanya fungsi bekerjanya dibalik, pada dasar metodenya bahwa untuk menghitung koefisien permeabilitas digunakan pemompaan dan pengambilan sampai pada permukaan air tanah (piezometrik) melalui peresapan dasar, sedang untuk penelitian ini dibalik, yaitu kemampuan meresapkan air melalui lobang dasar pipa dalam waktu tertentu. Lokasi penelitian lapangan pada 5 (lima) lokasi sub kawasan KIP, dan tiap-tiap lokasi diadakan penelitian 4 (empat) tempat secara acak dan merata mewakili setiap lokasi. Hasil penelitian dari 20 titik pengamatan dengan mengambil harga $t$ secara periodik dan harga $h$ awal dan harga $h$ akhir yang bervariasi dapat dihitung nilai K. Untuk menentukan harga $S$ yaitu faktor geometrik, karena peresapan hanya melalui dasar saja, digunakan harga $\mathrm{S}=4 \mathrm{R}$ (Forcheimmer 1930, Dachler 1936, Aravin 1965).

\section{HASIL DAN PEMBAHASAN}

Rekayasa sistem drainase berwawasan lingkungan mengacu pada pemilihan sistem yang tepat dan telah direkomendasikan yaitu pola TRAP. Sistem drainase dengan pola TRAP dimaksudkan untuk mengatasi permasalahan banjir di musim hujan dan krisis air di musim kemarau. Rekayasa sistem drainase berwawasan lingkungan difokuskan pada kemampuan sistem drainase dalam meresapkan air hujan ke dalam tanah. Berikut ini diuraikan hasil rekayasa sistem drainase berwawasan lingkungan berupa sumur resapan, saluran resapan dan kolam resapan.

\section{Sumur Resapan}

Sumur resapan diperuntukkan meresapkan air hujan yang melimpah dari PAH. Perencanaan sumur resapan mempertimbangkan tinggi muka airtanah dan luas atap sehingga diperoleh dimensi dan sebaran sumur resapan. Dimensi sumur resapan adalah ukuran-ukuran meliputi jari-jari (R), tinggi dinding sumur kedap air yang direncanakan $(\mathrm{H})$. Penentuan dimensi sumur resapan rencana (Qr), digunakan data debit air rancangan yang masuk ke dalam sumur resapan, koefisien permeabilitas tanah $(\mathrm{K})$, waktu pengaliran $(\mathrm{Tc})$, dan faktor geometrik sumur resapan (F). Diperoleh nilai F diperoleh 2,51 m untuk sumur resapan diameter $80 \mathrm{~cm}$ dan $3,14 \mathrm{~m}$ untuk sumur resapan diameter $100 \mathrm{~cm}$.

Hasil perhitungan sumur resapan dapat dilihat bahwa efektifitas penggunaan sumur resapan diameter $80 \mathrm{~cm}$ dan kedalaman 4 meter pada kawasan terbangun (C: 0,90 ) sebesar 29,96\%, lahan campuran (C: 0,50) sebesar 26,97\%, ruas jalan (C:0,80) sebesar $0 \%$ dan lahan terbuka (C: 0,30) sebesar 17,98 \%. Diperoleh angka rata-rata sebesar $18,73 \%$. Nampak jelas bahwa semakin besar dan kedalaman sumur resapan maka semakin banyak air yang diresapkan ke dalam tanah. Sebaran titik sumur resapan dipengaruhi oleh koefisien tutupan lahan $C$, semakin besar nilai $C$ berarti semakin kedap permukaan tanah sehingga membutuhkan sumur resapan semakin banyak sebagai pengganti media resapan akibat penggunaan lahan kedap air.

\section{Saluran Resapan}

Kajian kebutuhan saluran resapan berdasarkan intensitas hujan dengan kala ulang 5 tahun, luas DAS, waktu konsentrasi, debit rencana dan dimensi dan jarak sumur resapan. Debit rencana dihitung dengan rumus rasional sebagai berikut :

$$
Q r=0,278 \text { C.I.A. }
$$

Ketentuan dimensi, jumlah dan jarak sumur resapan pada saluran resapan berdasarkan ketentuanketentuan, antara lain; tipe/kelas jalan (ROW: Right Of Way), diameter, kedalaman dan jarak pemasangan sumur resapan pada saluran resapan. Kriteria yang dipakai disajikan pada Tabel 1.

Jumlah sumur resapan pada saluran drainase ditentukan berdasarkan kemampuan setiap sumur 
resapan dalam menampung dan meresapkan air kedalam tanah. Berdasarkan rumus diatas maka kemampuan saluran peresap dipengaruhi oleh diameter dan kedalaman sumur serta permeabilitas tanah setempat. Saluran resapan berfungsi mengalirkan dan meresapkan sisa aliran dari sumur resapan dan limpasan permukaan pada saat terjadi hujan. Sumur resapan dipasang di bagian dasar saluran sepanjang saluran resapan dengan jarak tertentu sesuai dengan kebutuhan perencanaan.

Rekayasa saluran resapan diperoleh hasil efektifitas kemampuan saluran dalam meresapkan air kedalam tanah sebesar 2,52 \%. Efektifitas saluran resapan dipengaruhi oleh jarak, diameter dan kedalaman sumur resapan yang dipasang di dasar saluran. Faktor utama penggunaan sumur resapan pada rekayasa saluran resapan ini dipengaruhi oleh nilai permeabilitas tanah (K) dan kedalaman muka air tanah. Nilai resapan akan semakin tinggi seiring dengan tingginya nilai $\mathrm{K}$ dan banyaknya jumlah sumur resapan.

\section{Kolam Resapan}

Kolam resapan pada studi ini berupa embung, kolam dan bangunan lain dibangun untuk menampung penuh air di musim hujan dan kemudian dimanfaatkan selama musim kemarau untuk melayani berbagai kebutuhan. Menurut pencatatan hujan di Sta. Karangploso, bahwa terdapat bulan hujan dan kemarau hampir berimbang pada kisaran masing-masing berlangsung selama 6 (enam) bulan. Dengan demikian kapasitas tampung kolam yang dibutuhkan harus dapat memenuhi kebutuhan pada saat musim kemarau. Selain itu juga harus mempertimbangkan kehilangan air oleh penguapan di kolam dan resapan di dasar dan dinding kolam, serta menyediakan ruangan untuk sedimen. Kolam resapan air hujan mempertimbangkan kapasitas tampung, ketersediaan air dan kebututuhan air, sedimen dan kemampuan peresapan.

Kapasitas Tampung (Vn), kolam resapan akan menampung air sampai penuh di musim hujan, kemudian pada musim kemarau masyarakat akan menggunakan untuk berbagai kebutuhan penduduk seperti air baku, air minum, irigasi, dan ternak. Asumsi bahwa pada akhir musim hujan kolam ada pada kapasitas maksimum, maka kapasitas tampung kolam dapat dihitung dengan rumus:

$$
V n=V u+V e+V i+V s
$$

Perlu diperhatikan untuk menentukan kapasitas tampungan total suatu kolam $\left(\mathrm{V}_{\mathrm{n}}\right)$ harus mempertimbangkan volume air yang tersedia $\left(\mathrm{V}_{\mathrm{h}}\right)$ dan kemampuan topografi untuk menampung air $\left(\mathrm{V}_{\mathrm{p}}\right)$. Hal ini dimaksudkan agar kapasitas tampungan total yang diperlukan $\left(V_{n}\right)$ benar-benar dapat dipenuhi oleh volume/debit aliran yang tersedia selama musim hujan $\left(\mathrm{V}_{\mathrm{n}}\right)$. Demikian juga jika kondisi topografi $\left(\mathrm{V}_{\mathrm{p}}\right)$ tidak memungkinkan menampung volume air sebesar kapasitas tampungan total $\left(\mathrm{V}_{\mathrm{n}}\right)$ maka biaya konstruksi akan menjadi mahal, sehingga lebih baik untuk memenuhi kebutuhan maksimum suatu desa dibangun lebih dari satu kolam.

Kebutuhan Air dan Tampungan Hidup (Vu), kebutuhan air yang harus dilayani kolam diperhitungkan dari macam penggunaan air oleh penduduk. Untuk itu pendekatan yang dilakukan adalah dengan memperhatikan jumlah penduduk (KK), satuan kebutuhan air untuk masing-masing jenis penggunaan air, dan jumlah hari musim kemarau. Secara praktis rumusan umum pernyataan kebutuhan air total untuk tampungan hidup $\left(\mathrm{V}_{\mathrm{u}}\right)$ dihitung dengan rumus:

$$
V_{u}=J_{h} x J K K x Q_{u}
$$

Penentuan jumlah hari dalam musim kemarau dihitung dari jumlah hari dalam satu tahun dikurangi rata-rata jumlah hari hujan. Hasil dari perhitungan rerata jumlah hari pada musim kemarau adalah 240 hari. Kebutuhan air/KK/hari ditetapkan berdasarkan hasil perhitungan kebutuhan air yang harus dilayani dan tampungan hidup kolam selama periode satu tahun.

\section{Kapasitas Tampungan Hidup Kolam Resapan}

Volume sedimen $\left(\mathrm{V}_{\mathrm{s}}\right)$ berdasarkan pengamatan pada beberapa kolam yang berukuran kecil terjadinya pendangkalan kolam disebabkan oleh terbawanya sedimen oleh aliran yang masuk ke kolam (Tabel 2). Oleh sebab itu disarankan daerah tangkapan hujan agar ditanami tanaman yang mampu mengendalikan erosi. Dalam perhitungan kapasitas tampung kolam ditentukan secara praktis ruang setinggi 1,00 m diatas dasar kolam dipakai sebagai ruang tampungan sedimen $\left(V_{s}\right)$ ruang ini masih dapat dimanfaatkan selama belum terisi sedimen (Puslitbang Pengairan, 1994).

Jumlah Resapan $\left(\mathrm{V}_{\mathrm{i}}\right)$, Air didalam kolam akan meresap masuk kedalam pori atau rongga di dasar dan dinding kolam. Besarnya resapan ini tergantung pada jenis butiran tanah atau struktur batu pembentuk dasar dan dinding kolam. Secara teoritik perhitungan resapan air ini cukup rumit dan sulit dilakukan, besarnya resapan air kolam dihitung dengan rumus:

$$
V i=K . V u \text {. }
$$

Berdasarkan rumus di atas dapat dihitung kapasitas kolam resapan pada Tabel 3.

Rekayasa Sosial Sistem Drainase Berwawasan Lingkungan

Rekayasa sosial terhadap sistem drainase berwawasan lingkungan merupakan pelibatan peran 
serta masyarakat dalam upaya mendukung kinerja sistem drainase lebih memadai dan berkelanjutan. Rekayasa sosial meliputi kelembagaan dan teknis operasi dan pemeliharaan prasarana drainase secara rutin dan berkala. Peran serta masyarakat dalam penataan drainase menganut asas-asas demokratis, dan keterbukaan. Pendekatan ini merupakan dasar bagi pendekatan community driven planning yang menjadikan masyarakat sebagai penentu dan pemerintah sebagai fasilitatornya. Sejalan dengan proses perencanaan drainase yang iteratif, maka keterlibatan masyarakat ada pada setiap proses tersebut dan selalu tanggap dan mengikuti setiap dinamika dan perkembangan di masyarakat.

Peran serta masyarakat dalam studi ini dilibatkan melalui kegiatan forum dialog/penjaringan aspirasi yang menjadi satu kesatuan komponen dalam rekayasa sosial. Pelibatan masyarakat dimulai dari pembuatan gagasan, perencanaan dan pelaksanaan sampai dengan pembentukan kelembagaan drainase yang terdiri dari pemerintah, masyarakat dan swasta (KIP). Dengan dibentuknya lembaga tersebut maka akan menjamin proses perencanaan, pelaksanaan, pengawasan dan pemeliharaan berjalan dengan baik dan berkelanjutan. Pemeliharaan drainase memerlukan agenda rutin dan berkala, berikut diuraikan jenis pekerjaan pemeliharaan sebagai berikut:

(1) Pemeliharaan rutin; jenis pekerjaan pemeliharaan rutin antara lain; mengangkut sampah yang hanyut disaluran dapat dilakukan setiap hari, membuang tumbuh-tumbuhan (gulma) di saluran dapat dilakukan setiap hari.

(2) Pemeliharaan berkala, jenis pemeliharaan berkala meliputi; mengangkat sedimen yang ada di saluran umumnya dilakukan satu musim sekali.

Tabel 1. Kriteria Pemasangan Sumur Resapan

\begin{tabular}{cccc}
\hline Tipe Jalan & Diameter Sumur & Kedalaman Sumur & Jarak Sumur \\
\hline TIPE-1 ROW 20 & $0.40 \mathrm{~m}$ & $2.00 \mathrm{~m}$ & $10 \mathrm{~m}$ \\
TIPE-2 ROW 14 & $0.40 \mathrm{~m}$ & $2.00 \mathrm{~m}$ & $10 \mathrm{~m}$ \\
TIPE-3 ROW 10 & $0.40 \mathrm{~m}$ & $1.00 \mathrm{~m}$ & $5 \mathrm{~m}$ \\
TIPE-4 ROW 8 & $0.40 \mathrm{~m}$ & $1.00 \mathrm{~m}$ & $5 \mathrm{~m}$ \\
\hline
\end{tabular}

Tabel 2. Perhitungan Jumlah Volume Tampungan Hidup Kolam Resapan

\begin{tabular}{cccccc}
\hline No. & Sub Kawasan & $\begin{array}{c}\text { Jumlah KK } \\
\text { Terlayani Eksisting }\end{array}$ & $\begin{array}{c}\text { Kebutuhan Air } \\
(\mathrm{lt} / \mathrm{hr} / \mathrm{KK})\end{array}$ & $\begin{array}{c}\text { Jumlah Hari } \\
\text { Kemarau }\end{array}$ & $\begin{array}{c}\text { Volume Tampungan } \\
\text { Hidup }\left(\mathrm{m}^{3}\right)\end{array}$ \\
\hline 1 & SK-1 & 330 & 500 & 240 & $39,628.58$ \\
2 & SK-2 & 169 & 500 & 240 & $20,287.67$ \\
3 & SK-3 & 268 & 500 & 240 & $32,122.14$ \\
4 & SK-4 & 201 & 500 & 240 & $24,120.68$ \\
5 & SK-5 & 313 & 500 & 240 & $37,560.00$ \\
& TOTAL & 1,281 & 2,5 & 240 & $153,719.07$ \\
\hline
\end{tabular}

Sumber : Hasil Perhitungan, 2009

Tabel 3. Perhitungan Kapasitas Kolam Resapan

\begin{tabular}{ccccc}
\hline \multirow{2}{*}{$\begin{array}{c}\text { No. } \\
\text { Kawasan }\end{array}$} & $\begin{array}{c}\text { Kebutuhan Tampungan Hidup } \\
\left(\mathrm{m}^{3}\right)\end{array}$ & $\begin{array}{c}\text { Nilai Faktor Kelulusan Air } \\
(\%)\end{array}$ & $\begin{array}{c}\text { Jumlah Resapan } \\
\left(\mathrm{m}^{3} / \text { tahun }\right)\end{array}$ \\
\hline 1 & SK-1 & $39,628.58$ & $25 \%$ & $9,907.14$ \\
2 & SK-2 & $20,287.67$ & $25 \%$ & $5,071.92$ \\
3 & SK-3 & $32,122.14$ & $25 \%$ & $8,030.54$ \\
4 & SK-4 & $24,120.68$ & $25 \%$ & $6,030.17$ \\
5 & SK-5 & $37,560.00$ & $25 \%$ & $9,390.00$ \\
\end{tabular}

Sumber : Hasil Perhitungan, 2009 


\section{KESIMPULAN}

1. Efektifitas penggunaan sumur resapan diameter 80 $\mathrm{cm}$ dan kedalaman 4 meter pada kawasan terbangun (C: 0,90) sebesar 29,96\%, lahan campuran (C: 0,50) sebesar 26,97\%, ruas jalan (C:0,80) sebesar $0 \%$ dan lahan terbuka (C: 0,30$)$ sebesar $17,98 \%$.

2. Penggunaan saluran resapan berdasarkan ketentuan tipe jalan ( $R O W$ : right of way), diameter sumur resapan $40 \mathrm{~cm}$, kedalaman sumur 2 meter dan jarak antar sumur 10 meter, diperoleh efektifitas saluran resapan sebesar 2,54\%.

3. Kolam resapan sebagai media drainase berwawasan lingkungan di Kawasan Industri Piyungan mempunyai kontribusi peresapan sebesar $25 \%$ (38.429,77 m3/tahun) dari kapasitas total debit penampungan $152.719,07 \mathrm{~m} 3 /$ tahun.

4. Hasil analisis sistem drainase berwawasan lingkungan dengan koefisien permeabilitas tanah $4,66 \mathrm{~cm} /$ jam $\left(1,3 \times 10^{-3} \mathrm{~cm} /\right.$ detik $)$ diperoleh nilai peresapan untuk sumur resapan: $18,73 \%$, saluran resapan: $2,54 \%$ dan kolam resapan sebesar $25 \%$.

5. Rekayasa sistem drainase berwawasan lingkungan paling efektif menggunakan sumur resapan dipadukan dengan kolam resapan.

6. Rekayasa biologi dengan cara penanaman vegetasi lokal yang mampu menyimpan air sekaligus sebagai peneduh adalah pohon akasia, randu, jati, mahoni dan ketapang. Pohon-pohon peneduh ditanam di sepanjang median jalan, area terbuka dan sekitar kolam resapan.

7. Rekayasa sosial berupa pelibatan semua pemangku kepentingan (pemerintah, masyarakat dan swasta) berperan serta dalam pendampingan gagasan awal sampai dengan pemeliharaan prasarana drainase, sehingga menjamin sistem drainase berwawasan lingkungan dan berkelanjutan.

\section{DAFTAR PUSTAKA}

Anonim. (2001). UNEP. Environmental Management of Industrial Estates

Anonim. (2001). "Analisis Dampak Lingkungan Kawasan Industri Piyungan”. Badan Pengendalian Dampak Lingkungan. Kabupaten Bantul.

Coulter, Christ, B., Randy, K., Kolka, and James, A. Thompson. (2004). Water Quality in Agriculture. Urban. and Mixed Land Use Watershed. Journal of the American Water Resources Association (JAWRA). 40(6), 1593-1501.

Departemen Perindustrian dan Perdagangan Provinsi D.I. Yogyakarta. (1997). Penyusunan Rencana
Teknis Pendirian Kawasan Industri Kulit Provinsi D.I. Yogyakarta.

Faisal. (2002). Evaluasi Rencana Teknis Kawasan Industri di Kecamatan Piyungan Kabupaten Bantul Provinsi D.I. Yogyakarta Berdasarkan Persepsi Pakar. Tesis. Yogyakarta. MPKD - Universitas Gadjah Mada.

Franzini, J.B., Lisley. R.L (1996). Water Resources Engineering. $3^{\text {rd }}$ Edition. New York. Mc.Graw-Hill Inc.

Gollnitz, D.W., Whitteberry, L.B., Vogt, A.J. (2004). Riverbank filtration: Induced Infiltration and Groundwater Quality. Journal American Water Works Association (AWWA). 96(12), 98-110.

Grigg, Neil. (1988). Infrastructure Engineering and Management. USA. John Wiley \& Sons.

Hindarko, S. (2002). Drainase Kawasan Daerah. Jakarta. Esha.

Hudson, W.R., Haas, R., Uddin, W. (1997). Infrastructure Management. USA. Mc Graw Hill.

Keputusan Gubernur Kepala Daerah Provinsi Daerah Istimewa Yogyakarta No.9 Tahun 2001.

Kodoatie, R. J. (2003). Manjemen dan Rekayasa Infrastruktur. Yogyakarta. Pustaka Pelajar.

Kontur, Ronny. (2003). Metodologi Penelitian Untuk Skripsi dan Tesis. Jakarta. Teruna Grafika.

Kusnaedi. (2002). Sumur Resapan Untuk Pemukiman Perkotaan dan Pedesaan. Jakarta. Swadaya.

Nadjaji, Anwar. (1998). Rekayasa Pengembangan Sumber Daya Air. Cetakan Pertama. Surabaya. Kartika Yudha.

Rukmana, N, dkk. (1993). Manajemen Pembangunan Prasarana Perkotaan. Jakarta. LP3ES.

Soemarwoto, Otto. (2001). Ekologi. Lingkungan Hidup dan Pembangunan. Jakarta. Djembatan.

Sri Harto. (1983). Analisis Hidrologi. Jakarta. PT. Gramedia.

Subarkah, Imam. (1980). Hidrologi Untuk Perencanaan Bangunan Air. Bandung. Idea Dharma.

Sumarto,C.D. (1989). Hidrologi Teknik. Surabaya. Usaha Nasional.

Suripin. (2004). Sistem Drainase Perkotaan yang Berkelanjutan. Yogyakarta. Andi.

Torres, Allison. (2003). How Do We Solves The World's Water Issues? Water Environment and Technology. $15,50-57$.

Wignyosukarto, Budi. (2001). Pemanfaatan Decision Support System Untuk Perencanaan Sistem Drainase. Makalah. Malang. Kongres VII dan a VIII Himpunan Ahli Teknik Hidraulik Indonesia (HATHI). 